\title{
DWELLING WITH THE WATER
}

DOI: 10.18485/arh_pt.2020.7.ch49

\author{
_ Michele Montemurro \\ Dicatech Department, Polytechnic University of Bari, via \\ Orabona 4, 70121 Bari (Italy), michele.montemurro@poliba.it
}

\section{ABSTRACT}

The absence of an organic port strategy on the coasts of the Puglia Region has led to the development of many yachting expansion projects of ports and tourist landings, not included in a system vision in which every port and every city-port can assume a precise and identity feature within a sustainable transformation process of coastal and marine tourism. The choice of the city of Mola located in south of Bari was to abandon the previous expansion plans of the port, which provided for a huge increase in the available berths, in favour of a new vision of the water area of the port basin in the conditions of terramare, to be understood as a new urban space. A space that sees the mirroring of the ancient city in the sea as the founding condition of an ancient fishing and housing tradition. The research work developed in the Dicatech Department of the Polytechnic University of Bari has assumed the availability of timber generated by the VAIA storm (2018) in the Italian Alpine areas as an opportunity to rethink the wooden housing systems in the water, in continuity with the tradition and history of the places. The theme of the stilt house, of the "Trabucco" (cantilevered wooden structure on the rocks dedicated to fishing with " great balance") as well as that of the houseboat were faced by identifying the construction and typological grammars to redefine the protected water place of the new port of Mola as an urban place and place of representation of the relation between the city, its seafaring and the sea.

KEYWORDS _ waterfront, port, stilt house, floating house, coastal cities

\section{WATER CITIES}

In recent decades, water cities have played a central role within the various territories, demonstrating how much the presence of water (sea, river, lake or lagoon) is a crucial resource as a catalyst for regeneration processes not only of large urban realities, but also of small and medium-sized cities overlooking the water. The scale of the interventions, the territorial and urban strategies, the management of the transformative processes, are some of the issues that emerge from the complex city-port relationship, synthesis of the ideological and scalar contradictions between architectural, urban planning and design (Giovinazzi, 2008). The Waterfront Redevelopment has become the driving force for the development of entire urban areas according to two different scales: the vast industrial one (more typical of the great ports of Northern Europe), characterized by entire abandoned port areas, often huge empty ones, placed now in central position; the more contained, urban (more typically Mediterranean), characterized by often natural port sites, internal or close to the consolidated fabric, where the relationship with the city is denied.

In the first case, the presence of wide abandoned areas has allowed the design of new neighborhoods or entire "parts" of cities (Hafen-City in Hamburg, Borneo Sporenburg in Amsterdam, etc.). In the second case, the intervention concerns the recovery of the port as a real water square, recon- 
structing the relationship between city and water (Marseille, Genoa).

The project for the Old Port of Genoa has clearly shown how the "rediscovery" of water in contexts in which this relationship is denied, is capable of triggering transformation processes for the entire urban and territorial reality.

The port, with its multiple meanings, infrastructural, cultural, residential and tourist, is often an area bounded and separated from the city, an area rooted in the place but at the same time projected far across the sea which, through regeneration and connection processes, it can go back to being the representative and identifying place of the coastal city, a new space in the city where water becomes an element of continuity that welcomes new forms of living (co-housing), work (co-working), commercial, recreational and receptive.

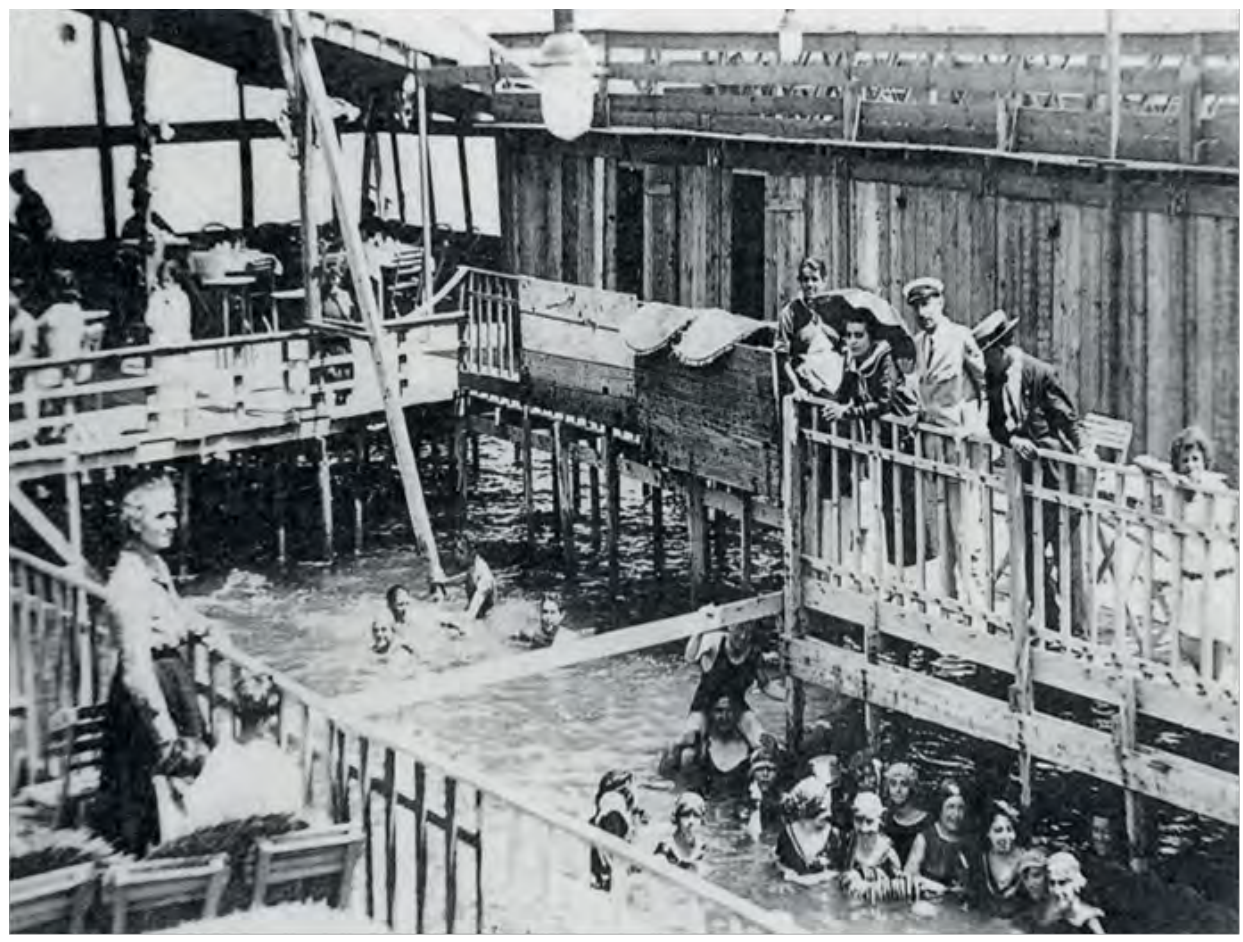

_ Figure 1: 1930 (about), Mola di Bari (Puglia, Italy), stilt structure offshore for swimming and leisure. https://www.citta-nostra.it/lalbum-dei-ricordi-mola-comera/

The research', of which this essay exposes partial results, assumes this complexity considering the port as a constituent part of the city and a place of living which, giving collective value to water spaces as new centralities, without interfering with the necessary autonomy of the infrastructure, can reconstruct the urban continuity and identity of the coastal city.

The research developed in two complementary phases, an analytical one aimed at the study of the topic, the definition of the field of investigation, the definition of the appropriate research tools and methods; the other design aimed at verifying through the project the knowledge acquired in the first phase, taking Mola di Bari as a paradigmatic case study.

\footnotetext{
1 The research was developed within the "Dwelling with the water" Masters's Degree Workshop, consisting of undergraduates A. Grossi, M. Farinola, G. Guerra, A. Tuberoso, supervisor prof. Michele Montemurro, together with prof. Nicola Martinelli and arch. Nico Berlen, with the contribution of profs A. Fraddosio, M. leva, A. Labalestra, V. Ardito.
} 


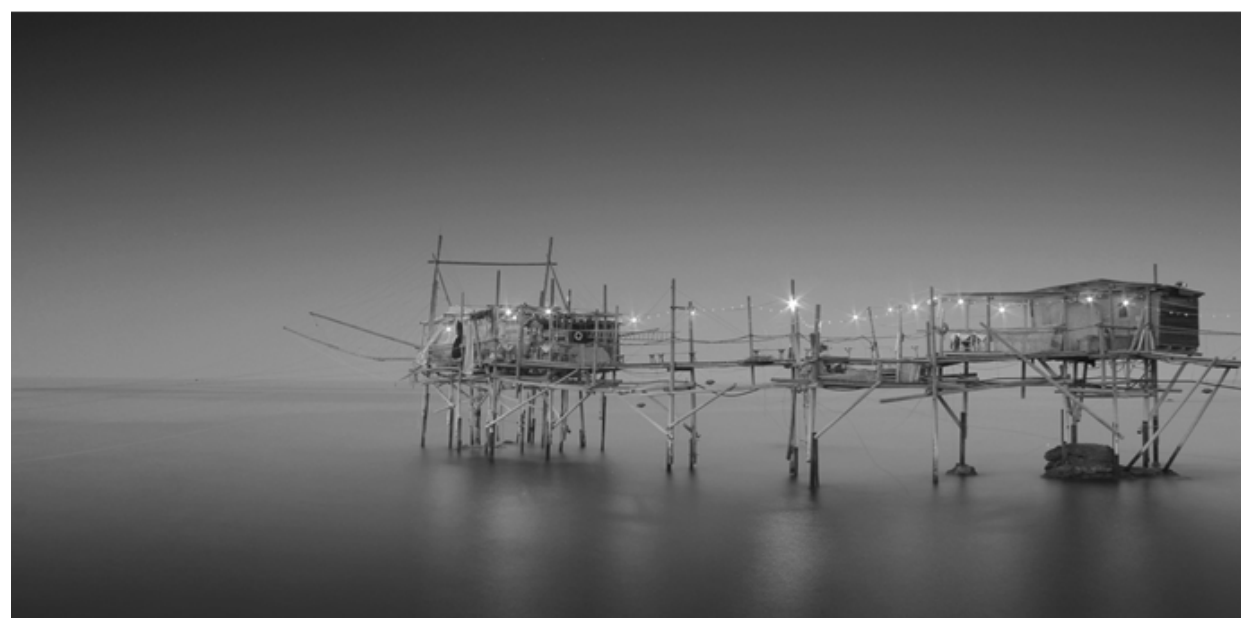

_ Figure 2: "Trabucco" is a kind of fishing machine built along the coast of Puglia. http://colibrimagazine. it/trabucchi-termoli/

\section{CITY AND PORT. FORMS OF GEOGRAPHY AND URBAN STRUCTURE}

«The cities with port are distinguished from the port-cities. In the former the ports were built out of necessity, in the others they were created according to the nature of the places; here is a mediation or a completion, there the beginning or the center. There are ports that always remain only landings or anchorages, while others become stages and finally worlds (...) We can also distinguish ports from other elements: if they were opened by the course of a river, if they were chosen or imposed by the mainland thrusts or even from the hinterland or if it was finally wanted by the sea. The nature of the ports depends on the way the sea is inside it, on the subjects to which it is accessible: The Atlantic and Pacific are seas of distance, the Mediterranean a sea of propinquity, the Adriatic a sea of intimacy. " (Matvejevic, 1987).

For Fernand Braudel, in fact, there is a unity of the Mediterranean space due to a network of cities and villages and structured on a set of maritime and terrestrial streets connected to each other and therefore of cities that hold hands and that projects on the territory a precise model of social organization. The construction of city-port give form to the relationship between nature and artifice, forms of geography and the settlement system, highlighting the way in which architectures capable of interpreting the water limit are characterized as primary elements of the city and urban centrality. The water enclosed by the piers assumes form and dimension as a space and, like that of stone, can constitute the element of continuity of the urban places in which the settlement and housing forms are compared and arranged according to specific relational grammars capable of enhance the spatial values of both river and marine port basins, by means of architectures and urban spaces that acquire identity through their relationship with water. The port is an element of identity and recognizability of the coastal city (Mileto, Ostia, Messina) and organic part of the urban structure building continuity between urban spaces and water spaces (Trieste).

Ports are also placing of fishing, of material culture linked to the sea, of the craft traditions of the seafaring and its rites. Spaces shared and therefore representative of the community of small and medium-sized coastal cities. The progressive closure of the port areas and the creation of customs barriers determinate the separation of the cities from the ports, making the spaces on the water like autonomous, infrastructural "citadels", within which, the filled parts to the sea redesign the coastal limit, removing the sea from the land and definitively modifying the original coastline, the matrix of the urban form and the waterfront. 


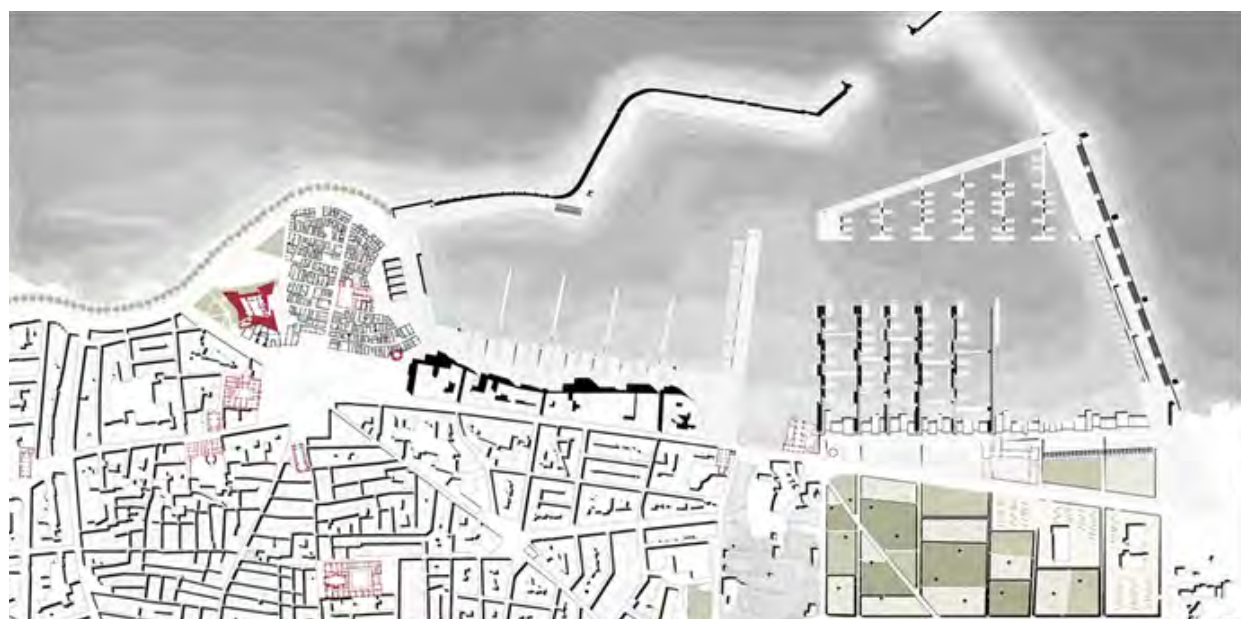

_ Figure 3: The project for the new port of Mola di Bari. The pier perpendicular to sea shore divide the old
port from the new, in correspondence of the "lama" that comes from internal territories and that separate
city from cultivated territories on the coast. The projects interpret the space of the new port with stilts
houses on the coast, the new pier with "Trabuccos" and the houseboat of the hotel, and, for ending, the
floating house quarter. (this figure was taken by "Dwelling with the water" Degree Workshop)

«Ports have generally been mentioned only in relation to sea voyages; stops towards other ports of call, places of storage and exchanges, open to the rest of the world first of all (...) In this long history of travel we have only rarely focused on the fact that ports were also extraordinary cities" (Fortier, 1987). The landscape of the port is built from the forms of the soil (docks and piers), large-scale architectures, the basin (large void) from their ability to interpret the geography of the place. "[The port] Universe of shapes and places that seems to detach itself from the ground to be in that geographical limit in which we all want to participate " (Rossi, 1990). The sense of the port is twofold and inverse: it is a place where activities develop separate from the city, characterized by its offscale architectures, such as cranes, silos, lighthouses, maritime and customs stations, shipyards, symbolic forms and elementary figures of the port infrastructure; but its piers, limits of the water basin, and its quays, extensions of urban paths beyond the shore, constitute a spatial device to experience a poetics of unpublished spaces linked to its large voids, beyond the city.

In the vision from the sea, the large structuring elements of the port reveal its relationship with nature and with the formal structure of the urban landscape. The waterfront is often a synecdoche of the shape of the city, to be defined through the dialectic between the land line and the vertical elements (the waterfront of Castel Fusano by A. Libera or the project for Buenos Aires by Le Corbusier) which takes on the value of "urban door" and faces of the city. Reconnecting the city and port therefore means connecting two entities with different spaces, through the construction of places where the city and the sea interact. Cities of water are often built by subtracting space from water, filling and founding in stable forms (Venice, Amsterdam), but also by supporting water with elastic (stilts) or mobile forms (Amsterdam, Antwerp). Unlike the inner cities, the water cities have a more complex structure for the different types of relationship that is established between the house and the different forms that the public space assumes ("water square" and "stone square", canals, streets, waterfront, docks, etc.). The new experimental neighborhoods of houseboats, ecological and sustainable, such as Jiburg in Nederland, are expression of a culture that has learned to live in balance between land and water, derive from a constantly renewed tradition, able to offer a settlement, housing model and spatial identity, of general value, consistent with the territory features. 


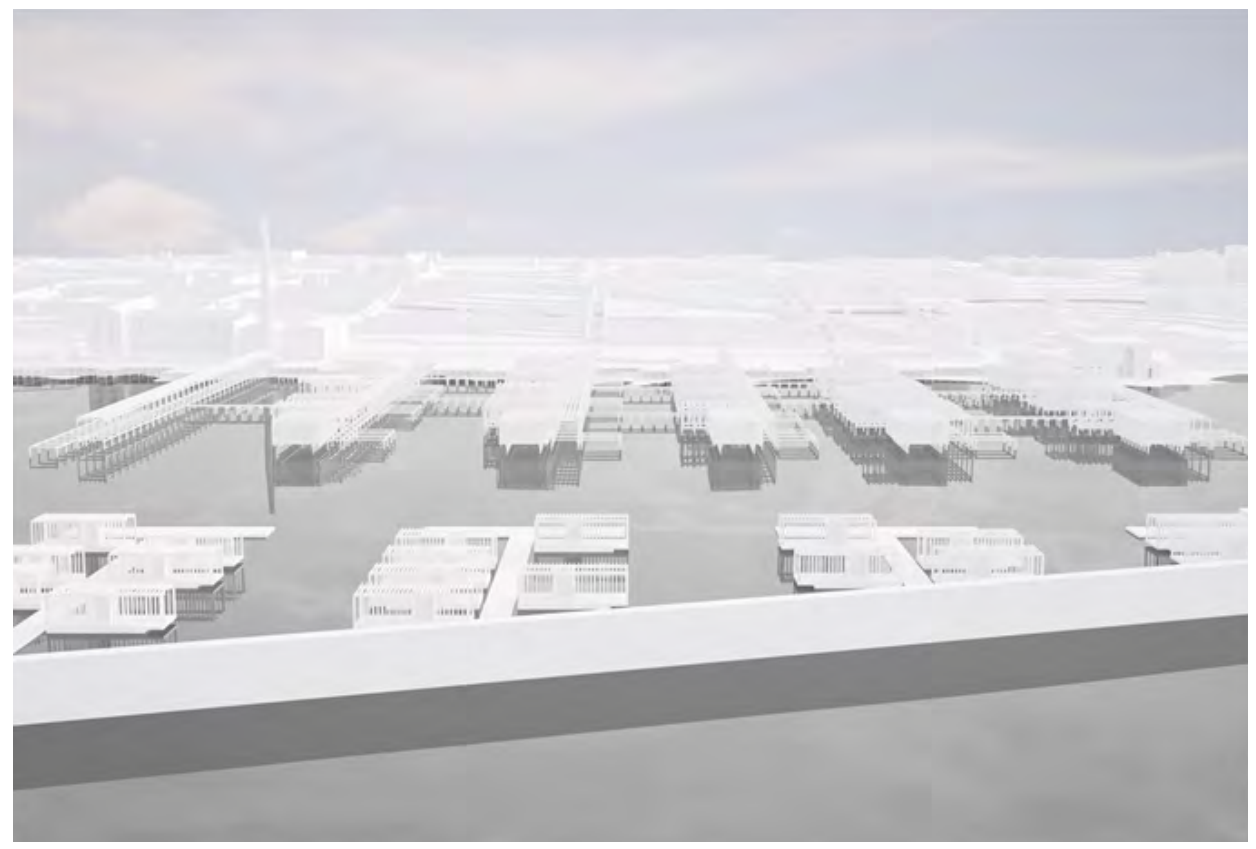

_ Figure 4: The project for the new port of Mola di Bari. The stilt houses saw from the pier of the floating houses. (this figure was taken by "Dwelling with the water" Degree Workshop)

\section{HOUSING IN URBAN WATER SPACES: THE STABLE HOUSE, THE FLOATING-HOUSE, THE HOUSEBOAT}

The port space can be interpreted as a place where different realities confront each other, a water square in which the ancient city, the waterfront, the places of fishing, the market and the fishing boats, the shipyard and the boats, the transport, housing, work and commerce are spaces and activities that convey the identity of the seaside city, through the sharing of forms linked to the wooden construction tradition of buildings, boats and port equipment.

The main port cities of the Adriatic, the arsenals, the piers, the "briccole", the large roofs, were often built using wood and naval construction techniques also in civil construction, developing widespread and shared traditions. A koinè of coastal cities based on sharing updated construction techniques and renewed housing forms in wood. Wood expresses the memory of the lost continuity between forest and sea, between cultivation, construction and navigation. The frame construction, light for boats (furniture) or heavy for fixed structures, such as pontoons, platforms and stilts. It is no coincidence that the pile dwelling forms have developed coevally in the world and in Europe, sharing form and construction in a diatopic way to live in harmony with water. The stilt house has consolidated itself as a settlement and housing form and an element of sharing in that strip of landscape between the mainland and

the water defined as "terramare", a place for recreational activities such as bathing and productive activities such as fishing, overcoming difficulties such as coasts inaccessible or tides. The contrast between lightness and "provisionally", as opposed to the stability and "fixity" in the water of the light wooden construction, connotes this type as an appropriate and stable form of settlement of water spaces, an ideal extension of urban space beyond the limit of the coast, in continuity with the city, but representative of the port condition. The fixity of the stilt house is contrasted by the mobility of the fixed or mobile houseboat whose shapes originate in the nautical tradition. 

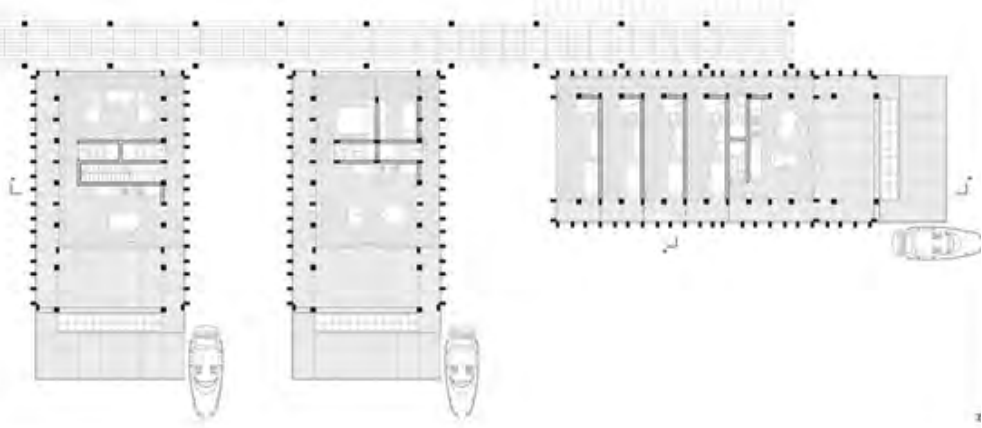

_ Figure 5: The project for the new port of Mola di Bari. Intermediate plans of the houses on stilts. (this figure was taken by "Dwelling with the water" Degree Workshop)

The floating house and the houseboat are distinguished by the degree of mobility that their nature of boat can guarantee, within the spaces and waterways of those cities and those places where the land breathe with the water. The floating house takes water as a foundation site but often belongs to a settlement structure, that is, to an urban form and to its system of planned relationships between housing and collective space. The houseboat instead establishes new relationships with the mainland through the landing, giving new meaning to public spaces along the water, often expressing the transformation induced by an unexpected presence that causes estrangement in places of custom.

\section{MOLA PORT AND CITY. NEW SETTLEMENT AND DWELLING WOODEN MODELS IN THE WA- TER SPACES OF THE MEDITERRANEAN CITY}

"The piers are the worthiest defenders of the ports" (...) they are as different as the ports themselves: some have sprung up naturally from the coast and leaned on it, others are just a pile of stones carried by who knows where and thrown in bulk on the seabed. On the first you can walk and laze in the others you can only unload the goods and trade» (Matvejevic, 1987).
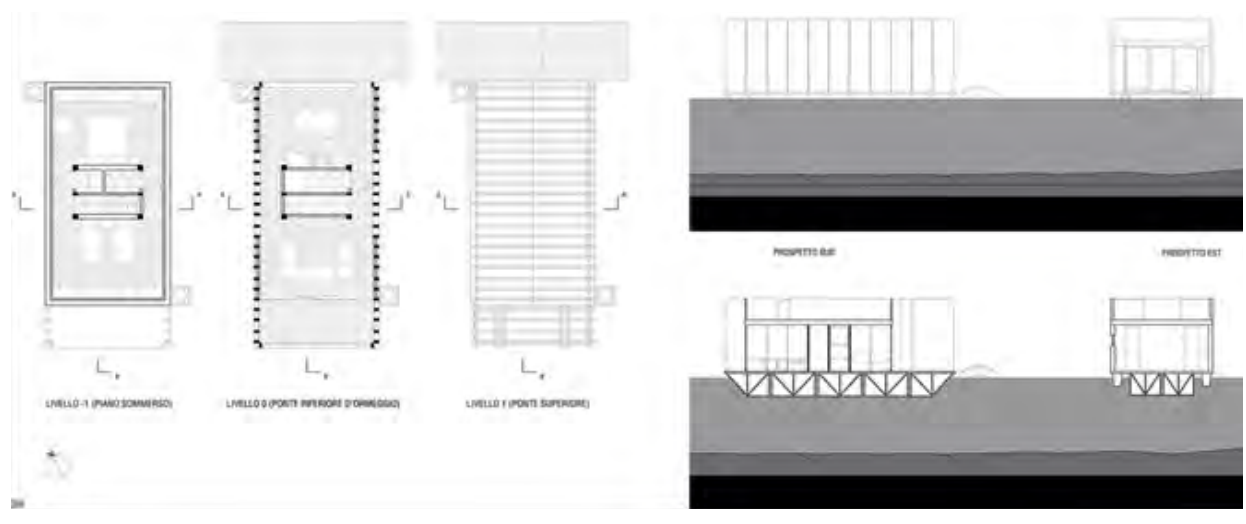

_ Figure 6: The project for the new port of Mola di Bari. Plans of the floating house and sections of houseboats. (this figure was taken by "Dwelling with the water" Degree Workshop) 
Along the Italian Adriatic coast from Venice to Puglia, constructive traditions have developed related to fishing and navigation that mark the history and material culture of numerous coastal towns. The city of Mola ${ }^{2}$, located south of Bari is among these: its tradition of ax masters, skilled builders of wooden fishing boats, combined with the knowledge of fishermen and farmers, capable of taking care of the agricultural area overlooking the sea, have built the cultural and productive identity of its community and its territory, linked not only to the close relationship between land and sea, but also to an interrupted tradition of inhabiting the sea with stilts systems, mediators between the rocky coast and water, which has characterized the image of the Adriatic seaside cities of Puglia for many years.

A tradition that refers to two types of structure that express the value of living between land and sea: the traditional pier / stilt house dedicated above all to bathing and recreational structures and the "Trabucco", a wooden cantilevered structure on the rocks dedicated to fishing. In the project the new port is assumed as a water square, a projection of the city into the space of the sea, in which, in the place of the limit between the land and the sea, whose shape constitutes the etymological root of the shape of the port itself (Marti Aris, 2007), new forms of living (working) are experimented. The identified housing forms, the stilt houses, the houseboat and the houseboat are arranged in continuity with the urban structures, building "neighborhoods" within the port basin which becomes the place of the mixite between housing, production, accommodation and recreational functions. The pile-dwelling settlement generates an urban fabric located east of the Madonna di Loreto, an ideal extension of the former Gaslini into the sea, a new nucleus of services for the sea, for boating and for bathing, facing the ancient city. The floating house system and the mobile houseboat system are located close to the new pier and a new transverse arm parallel to the coast that encloses the new harbor basin, closing to the west on the Madonna di Loreto pier, as elements of the port similar to the fishing infrastructure. They are an interpretative form of the third system, the receptive one and define another neighborhood located between the open sea and the pile dwelling system, giving new value to the breakwater pier. The new "Trabucchi", located outside the pier and intended for fixed-fishing tourism and catering, complete the accommodation spaces. The theme of the stilt house, of the "Trabucco" and that of the houseboat were tackled by identifying the constructive and typological grammars to redefine the protected water place of the new port of Mola as an urban place and place of representation of the link between the city, the his seamanship and the sea. The aim of the project was to identify the morphological and constructive elements of the stilt house, the houseboat and the houseboat and to describe the significant relationships that they establish with the forms of nature (the sea, the coasts, the connecting structures between land and water) with the forms of the port, identifying the appropriate analytical categories that allow to define the grammars of their aggregative forms according to the control of the transformations / modifications that can be made to the city and its urban spaces without altering its formal and topological value.

\section{CONCLUSIONS}

The absence of an organic port strategy on the coasts of the Puglia Region has produced numer-

2 The ancient center of Mola di Bari, with the castle, is built on a point extending into the sea from which extends the pier that protects the ancient port, between the historic center and the natural limit of the urban fabric constituted by the "lama". The new pier, that define the basin of the new port, is rooted further east including the strip of coast on which the area of the ex Gaslini oil mill overlooks. The route that connects Mola to Rutigliano generates a system of measurement and structure of the territory called "Capodieci" that is a system of parallel roads and perpendicular to the coast that develop east and west of the ancient center every 500 meters, ordering also agricultural parceling out. The church of the Madonna di Loreto marks the presence of the first "Capodieci" in the east and the separation between city and countryside at the mouth of the "lama" in the harbor. 
ous and incongruous expansion projects for the purpose of pleasure boating, favoring an inorganic development of the coast, often compressed between illegal construction, undermined naturalness and uneven growth of the accommodation / port facilities. The solution proposed in the research is to consider the expansion plan of the water area of the port basin as a new urban space to enhance the identity of the seaside city within a process of sustainable and organic transformation of coastal and marine tourism through the experimentation of new forms of living (working) in harmony with the water and the forms of the coast. The identified housing forms, made of wood according to naval construction techniques, i.e. the pile-dwellings, the houseboat and the houseboat re-link the broken thread of the housing tradition of the Apulian seaside city and are arranged in continuity with the urban structures in the Terramare space, building "neighborhoods" within the port basin. Coastal landscape, city and sea, with its rituals that mark the time of day, establish the invariant elements of a new harmony capable of renewing tradition, enhancing the identity values of these places and offering an appropriate and sustainable response to enhance the beauty of extraordinary places by nature.

\section{REFERENCES}

_ Amirante, Roberta, and Bruni Francesca, and Santangelo Maria Rosaria. 1993. II Porto. Napoli: Electa.

_ Braudel, Fernand. 1985. Il mediterraneo. Paris: Flammarion.

_ Bruni, Francesca, and D'Agostino Angela, Santangelo Maria Rosaria. 2002. La trasformazione delle aree portuali. Napoli: Edizioni Scientifiche Italiane.

_ Fortier, Bruno. 1987. "Il sogno di città macchine: porti e arsenali all'inizio del XIX secolo". In Arsenali e città nell'occidente europeo, edited by Concina Ennio. Roma: NIS.

_ Giovinazzi, Oriana. 2008. Mediterranee, $n^{\circ} 111$, edited by Rodrigues-Malta, Rachel,.Aix-en-Provence : Presse Unviersitaire de Provence: pp.69-74

_ Matvejevic, Predrag. 1987. Mediterraneo. Un nuovo breviario. Milano: Garzanti.

_ Rossi, Aldo. 1990. Gabriele Basilico. Porti di mare, Udine.

_ Santangelo, Maria Rosaria. 1994. "Il Porto: città nella città", Civiltà del Mediterraneo, no.2 (jul-dec):

p.78-85. 